\title{
Health in correctional facilities is health in our communities
}

\author{
Katherine E. McLeod MPH, Ruth Elwood Martin MD MPH
}

Cite as: CMAJ 2018 March 12;190:E274-5. doi: 10.1503/cmaj.171357

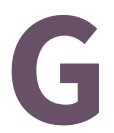

lobally and in Canada, incarcerated populations have a higher prevalence of both acute and chronic health conditions than the general population. ${ }^{1,2}$ People who experience incarceration have an increased risk of death across almost all disease categories and are particularly vulnerable in the weeks following release. ${ }^{3}$ Most people in correctional facilities have a history of trauma or abuse, mental health conditions or substance use. ${ }^{1,2}$ Many people in prisons experience homelessness, have low socioeconomic status and have low educational attainment. ${ }^{2,4}$ Incarcerated people are also more likely to have barriers to accessing health care and to have unmet health needs before their incarceration. ${ }^{5}$ Correctional facilities offer a unique opportunity to address the health care needs of underserviced populations and to connect people with services that will support them in the community. These aims may be more effectively achieved through governance and service delivery models that integrate prison health care with the general health care system.

On any given day in Canada, there are more than 14000 adults in federal custody and 25000 adults in provincial or territorial custody. ${ }^{6}$ In provincial and territorial correctional facilities, about half $(51 \%)$ of those in remand (i.e., detained before sentencing) are held in custody for one week or less, and more than half $(59 \%)$ of those sentenced are held for one month or less. ${ }^{6}$ With this short length of stay for most people in provincial facilities, the health of prison populations is closely connected with the health of communities. Improving health care services for people in prison therefore has the potential to affect the general population and the entire health care system; improving the health of people who experience incarceration may decrease health care costs, decrease rates of reincarceration and improve public health. ${ }^{?}$

The correctional context poses particular challenges to the delivery of health care services, such as overcrowding and security requirements. ${ }^{8}$ However, incarceration may also be an opportunity for people to focus on addressing health needs and to engage with health care because of decreased substance use, increased access to health services, and fewer competing priorities compared with living in the community. ${ }^{4}$ Continuity of care after release is a key component of ensuring care is effective. ${ }^{4}$ However, continuity is challenged by a disconnect between health care services in correctional facilities and those in the community.

\section{KEY POINTS}

- Integration of health care in correctional facilities with the public health care system is an opportunity to promote health and address the health care needs of underserviced populations.

- Limited evidence suggests that transferring responsibility for health care services in correctional facilities to the ministry of health improves service delivery, continuity of care, patient safety and population health outcomes.

- Health care professionals have a vital role in transforming care for this population as health managers, leaders and advocates.

In most jurisdictions in Canada and around the world, health care services for correctional facilities are governed by the ministry responsible for corrections and are delivered in parallel to, and disconnected from, the health care system that serves the rest of the population. In addition to challenging continuity of care as noted, this isolation of prison health care challenges community equivalence and the autonomy of health care providers. ${ }^{8}$ For example, if health care providers are employed by correctional authorities, providers may be in positions of conflict and may not be able to adequately advocate for indicated care and services. ${ }^{8}$

In October, British Columbia became the third Canadian province - after Nova Scotia in 2001 and Alberta in 2010 - to transfer responsibility for health care services in provincial correctional facilities from the ministry responsible for corrections to the ministry responsible for health. Worldwide, this integration has been implemented by several jurisdictions. Though there has been limited research evaluating governance models in this area, there are examples of positive system-level change that have resulted that illustrate the potential of integration. For example, the Liaison and Diversion program led by the United Kingdom's National Health Services provides supports and, where required, diverts people who come in contact with the criminal justice system who have a mental health disorder, learning disability or substance use issue to a more appropriate health care setting. ${ }^{9}$

In addition, jurisdictions that have implemented an integration model report improvements for providers, such as increased autonomy ${ }^{8}$ and reduced professional isolation. ${ }^{8,10}$ Improvements 
to health care are also reported including increased links with community health services, ${ }^{10}$ better health care quality, ${ }^{8,9}$ more coordinated response to public health risks such as communicable infections, ${ }^{8}$ improved assessment and understanding of health needs, ${ }^{8,10}$ increased patient safety ${ }^{8}$ and greater inclusion of incarcerated populations in public health initiatives. ${ }^{10}$ Further research is needed to examine and describe the effect of health care governance models on the health outcomes of people who experience incarceration.

Integration is a complex process, and jurisdictions report challenges such as the relationship between correctional and health care staff, establishing data sharing, ${ }^{8}$ equitable resourcing, ${ }^{8,10}$ prioritization of prison health, ${ }^{8,10}$ and resistance of community-based health services to engage with people who experience incarceration. ${ }^{8}$ These challenges illustrate the need for collaboration at all levels of the health care system to address the complex needs of this population.

Health care professionals and professional organizations have a vital role in realizing this vision for better health care and improved health outcomes for incarcerated populations. As health advocates, health care providers can advocate for change in policy and practice that will remove barriers to access and improve continuity of care. As health leaders and scholars, they can ensure that policy change results in meaningful improvements in health services and is accompanied by robust evaluation and continuous quality-improvement processes. As health managers and collaborators, they are positioned to leverage opportunities for population health interventions, so that incarcerated and formerly incarcerated populations are included in programs and services, and receive safe, effective care.

Other jurisdictions in Canada, including Ontario, Quebec, and Newfoundland and Labrador, are currently exploring or implementing the policy change of transferring health care in prisons to the ministry of health. This is an important opportunity for collaboration, evaluation and shared learning to improve the health of populations across the country.

\section{References}

1. Fazel S, Baillargeon J. The health of prisoners. Lancet 2011;377:956-65.

2. Kouyoumdjian F, Schuler A, Matheson FI, et al. Health status of prisoners in Canada narrative review. Can Fam Physician 2016;62:215-22.

3. Kouyoumdjian FG, Kiefer L, Wobeser W, et al. Mortality over 12 years of followup in people admitted to provincial custody in Ontario: a retrospective cohort study. CMAJ Open 2016;4:E153-61.

4. Abbott $P$, Magin $P$, Davison J, et al. Medical homelessness and candidacy: women transiting between prison and community health care. Int J Equity Health 2017;16:130.

5. Green S, Foran J, Kouyoumdjian FG. Access to primary care in adults in a provincial correctional facility in Ontario. BMC Res Notes 2016;9:131.

6. Reitano J. Adult correctional statistics in Canada, 2015/2016 [juristat]. Ottawa: Statistics Canada; 2017. Available: www.statcan.gc.ca/pub/85-002-x/2017001/article /14700-eng.htm (accessed 2017 Sept. 17).

7. Kinner SA, Wang EA. The case for improving the health of ex-prisoners. Am J Public Health 2014;104:1352-5.

8. Prison health and public health: the integration of prison health services [conference report]. London (UK): Department of Health and the International Centre for Prison Studies; 2004 Apr. 2. Available: www.osakidetza.euskadi.eus/contenidos/ informacion/sanidad_penitenciaria/eu_espetxe/adjuntos/integration.pdf (accessed 2017 Oct. 1).

9. Leaman J, Emslie L, Richards A, et al. Rapid review of evidence of the impact on health outcomes of NHS commissioned health services for people in secure and detained settings to inform future health interventions and prioritisation in England. London (UK): Public Health England; 2016. Available: www.gov.uk/government/ publications/health-outcomes-in-prisons-in-england-a-rapid-review (accessed 2017 Sept 12).

10. Hayton P, Boyington J. Prisons and health reforms in England and Wales. Am J Public Health 2006;96:1730-3.

Competing interests: None declared.

This article has been peer reviewed.

Affiliation: Faculty of Medicine, School of Population and Public Health, University of British Columbia, Vancouver, BC

Contributors: Katherine McLeod and Ruth Elwood Martin coauthored the manuscript. Both approved the final version to be published and agreed to be accountable for all aspects of the work.

Correspondence to: Ruth Elwood Martin, ruth.martin@ubc.ca 